\title{
INFLUENCIAS MEDIEVALES Y ORIGINALIDAD EN LA LITERATURA ESPAÑOLA DE FINALES DEL SETECIENTOS: EL CASO DE LA GADITANA MARÍA GERTRUDIS HORE
}

\author{
Frédérique Morand
}

Universidad de Alcalá de Henares

\section{RESUMEN}

Hablar de influencias medievales y originalidad en la poesía de finales del siglo XVIII requiere prestar más atención a los textos de María Gertrudis Hore (1742-1801), sin duda la escritora más importante de la centuria, al menos la más reconocida por sus coetáneos, y no sólo en Cádiz. Tras un breve repaso de la crítica más actual, nos hemos centrado en la originalidad de algunos de sus poemas de tipo anacreóntico. Destacamos a tres de ellos para el estudio. Dos manuscritos anteriores a su ingreso en la Orden de la Concepción (1778) y un tercero publicado en prensa tras vestir el velo. En relación a las influencias medievales, la poetisa eligió una de las obras maestras del arte poético religioso, el Stabat Mater Dolorosa, para crear, un argumento poco común en el ámbito literario de las Luces. El estudio comparativo de su traducción del Stabat con la de Lope de Vega nos pareció pertinente para destacar la capacidad de creatividad de la religiosa. Acercarse a la obra de la Hija del Sol a través de algunas composiciones cuyas temáticas se sitúan entre el género anacreóntico y la traducción del Stabat Mater revela sus lecturas heterogéneas así como su amplio espectro para crear. Erudición, talento e ingenio se esbozan claramente en sus rimas pero, quizás, haga falta una lectura atenta para descubrir todo lo que encierran.

Palabras clave: poesía anacreóntica, Stabat Mater Dolorosa, Lope de Vega, estudio comparativo, influencias medievales, originalidad.

\section{ABSTRACT}

When speaking of medieval influences and originality in poetry at the end of $18^{\text {th }}$ century, one has to pay attention to Maria Gertrudis Hore's work. She was arguably the 
most important female writer of that century and anyway the most famous among her contemporaries, not only in Cadiz. After a brief review of today's critique of her work, we will focus on the originality of three of her Anacreontic poems. The manuscripts of the first two were written before she entered the Conceptionist convent (1778). The third one was published in the press after she took the veil. Finally, while she wrote in the end of the $18^{\text {th }}$ century, the poetess chose to focus on one of the masterpiece of religious poetry in the $13^{\text {th }}$ century, the Stabat Mater Dolorosa, which is quite unusual in the literary context of the Enlightenment. From this perspective, the comparative study of her translation of the Stabat with the one of Lope de Vega seems to us, very relevant in order to show the capacity of creation of the nun.

Key words: Anacreontic poetry, Stabat Mater Dolorosa, Lope de Vega, comparative study, medieval influences, originality.

Podríamos citar a varias mujeres para conversar sobre literatura en la ciudad de Cádiz: la más conocida, Cecilia Böhl de Faber, su madre Frasquita Larrea, otras algo menos estudiadas como Manuela López Ulloa o bien Rosa Butler nacida en Jaén en 1821, y educada en Cádiz por sus tíos Rosa Butler y Antonio Izquierdo (Simón Palmer, 1991: 145-146)ํ․ Sin embargo, estaríamos departiendo sobre escritoras decimonónicas. Para ceñirnos a la temporalidad expresada hemos de detenernos, obviamente, en una gaditana nacida con algo de anterioridad, o sea, detenernos en una precursora, por decirlo de alguna manera.

\section{SU RECONOCIMIENTO EN VIDA}

María Gertrudis Hore (1742-1801) fue sin duda la escritora más importante de la centuria, al menos la más reconocida por sus coetáneos, y no sólo en Cádiz. Esa aseveración se deduce de las críticas localizadas en la prensa madrileña en las postrimerías del setecientos. El descubrimiento de comentarios alentadores, poco después de la publicación de todos y cada uno de sus poemas o cartas, aseguran al lector del siglo XXI el éxito y reconocimiento de la poetisa en vida. Detrás del llamado «Censor Mensual», así firmaba el crítico del Diario de Madrid, se esconde el poeta agustino Liseno, Fray Juan Fernández de Rojas, miembro del Parnaso Salmantino (Barabino, 1981: 379,

1. Vivió en Cádiz hasta 1841. Ossorio dijo: «Desgracias y pesadumbres la hicieron abandonar las letras hace muchos años»; colaboró con periodicos de Sevilla, entre otros, el Regalo de Andalucia (1849) y el Pensil gaditano (1857). Es de notar que tanto la familia Butler, de origen irlandés, como los Izquierdo tuvieron relación de parentesco y amistad con los Hore y Ley, apellidos respectivos de los padres de María Gertrudis, a quien vamos a estudiar. 
396-397, 429)2. Ese crítico exigente, cuya autoridad en la materia era de sobra conocida, fue el que comentó cada una de las composiciones de la gaditana. No alabó sus textos por razones de sexo, como se le recriminaba a veces a la hora de valorar creaciones de mujeres (Diario de Madrid, 9 de octubre de 1796: 905), ${ }^{3}$ sino que habló de «su facilidad en la poesía», de sus «sólidas máximas», de su filosofía, de «las útiles advertencias» que contenían algunas de sus anacreónticas, de «la belleza del estilo», de «la armonía del verso» (Diario de Madrid, 9 de septiembre de 1795: 1026). Asimismo, conocía «su instrucción en varias lenguas, su erudición escogida, su buen gusto e ingenio, juntamente con sus prendas personales» afirmando que dichas dotes «la han adquirido la admiración de cuantos la han tratado» (Diario de Madrid, 8 de junio de 1795: 651). El llamado «Crítico de los críticos» (Diario de Madrid, 16 de junio de 1795: 681-683) y, por tanto, los demás poetas salmantinos, al menos los que seguían vivos (Jovellanos, Meléndez Valdés) conocieron, aunque sólo fuese de oídas, a esta gaditana; sabían de buena tinta que hablaba varios idiomas y que era mujer culta, tuvieron constancia de su fama como fémina que cultiva las letras.

\section{LA VISIÓN DE LA CRÍTICA MÁS ACTUAL}

Ya conocíamos algo de la figura de la Hija del Sol sólo por la fama adquirida en la prensa madrileña. Cómo negarse a descubrir algo de las vivencias de una de las españolas más admiradas de su tiempo mientras que, según López-Cordón, escasean los datos sobre las escritoras del setecientos (LópezCordón, 2005: 221)4. En palabras de la profesora Urzainqui, «el interés que

2. Su participación en el periódico como crítico empezó el 4 de enero de 1795 hasta 1799, con una sola ausencia por indisposición en marzo, abril y mayo de 1797.

3. Citado por Zorrozua, 1999: 68.

4. «más allá de los nombres y escritos, nos faltan referencias precisas, incluso en el caso de las más reconocidas, sobre las que vertebrar una verdadera trayectoria biográfica e intelectual. Nada sabemos de su formación, de sus experiencias o de sus contactos y, en demasiados casos, sus vidas se circunscriben a una cronología tan breve que resulta imposible determinar rasgos imprescindibles de su personalidad y carácter, corriendo el riesgo de identificarlas demasiado con sus textos».

Es de notar que sólo e únicamente gracias al intercambio de informaciones que venimos realizando con Jorge Romero Braquehais (Málaga), descendiente de Esteban Fleming, el esposo de Gertrudis Hore, supimos que un genealogista irlandés se había interesado en la poetisa. Julián Walton tenía conocimientos muy precisos de su familia, había investigado en Cádiz, en la diócesis, o sea, había pisado ya en 1984 el camino que pensábamos haber abierto a finales del siglo pasado (Walton, 1984: 41-44). En nuestro caso, sólo gracias al intercambio de informaciones que venimos realizando con Jorge Romero Braquehais desde hace poco, descendiente de Esteban Fleming, el esposo de María Gertrudis Hore, supimos que un genealogista irlandés, Julián Walton, tenía

Anales, 23, 2011, pp. 67-93 
desde antiguo viene despertando la leyenda de su biografía, marcada por un oscuro episodio de adulterio (...) ha contribuido a realzar su obra dentro del Parnaso femenino del siglo XVIII ${ }^{5}$. Sin embargo, entre las numerosas poesías publicadas por firmas femeninas, la profesora eligió «como ejemplo de ellos, venido de la mano de una de las poetas más reconocidas», reeditar una poesía firmada H.D.S. (Urzainqui, 2006: LXXV-LXXIX).

Pilar Santisteban tampoco titubeó a la hora de hablar de la profusión de sus publicaciones comparando sus creaciones con las de otras españolas. Para Santisteban, dentro del panorama literario femenino, Gertrudis Hore aparecía como una excepción; de hecho la relacionó con Rosa Gálvez, Sor Ana de San Jerónimo y María Martínez Abello por sus frecuentes apariciones en prensa (Zorrozua, 1999: 196). Tampoco podemos apartar la crítica norteamericana, la primera en acordarse de ella en la década de los ochenta, aunque sólo citemos el último trabajo de Franklin Lewis en el que la profesora se interesó por el concepto de felicidad en sus versos (Franklin, 2004: 61-95).

Al igual que Rosa Gálvez fue la única dramaturga reconocida por la pluma de Moratín hijo, Gertrudis Hore fue la única recordada por el jefe de filas del grupo ilustrado más liberal, el conductor de toda una escuela de transición poética, José Manuel Quintana (Quintana, 1820: 44). Además, fue la única citada por la crítica franciscana como poetisa digna de representar la literatura espiritual de la orden en este siglo a menudo tachado de laico (Eijan, 1935: 371, 404-406). Como bien dijo Hormigón para Gálvez, y nunca mejor dicho para nuestra gaditana, sus versos encajan perfectamente dentro de la corriente ilustrada más progresista, «sin limitarse a una capillita determinada» (Gálvez, 1995: 15-17).

Si Gálvez comenzó su carrera literaria a partir de 1801 con el estreno y publicación, entre otros, de varias traducciones del francés, ese fue el año de la desaparición de Gertrudis Hore. La poetisa fue, como lo subrayó López-Cordón refiriéndose a Gálvez, una de estas féminas pertenecientes a un grupo de especial interés para conocer el «prototipo de mujer nueva, que lucha por abrirse camino en el mundo literario y se aparta de los moldes establecidos»(López-Cordón, 2005: 216). Fuese ella, fuese Rita de Barrenechea, Margarita Hickey, Inés Joyes, la Condesa de Montijo u otras de estas damas letradas nacidas en España en el setecientos, cada una ilustraba a su manera «el latido del universo femenino en el Siglo de las Luces» (Urzainqui, 2006: XVI).

conocimientos muy precisos de la familia de la poetisa, o sea, que había pisado el camino que pensábamos haber abierto (Walton, 1984: 41-44).

5. V. Morand, 2009: 387-412. 
Hablar de influencias medievales y originalidad, según indica el título, requiere prestar más atención a sus textos. Pero, antes de adentrarnos en el análisis de los versos, enlacemos nuestros conocimientos con los de algún autor gaditano decimonónico para presentar a Fenisa. ¿Cómo menospreciar los avances biográficos de la investigación si la propia definición de la poesía está estrechamente ligada a la del poeta y a su estatus social, además de variar según las épocas y las sociedades? (Marti, 2001: 1).

\section{ALGÚN ARTÍCULO PUBLICADO EN SU CIUDAD}

En un periódico llamado La Academia, el director José del Toro escribió sobre la desaparecida poetisa. Su manera de acercarse a ella, ochenta años tras su fallecimiento, marcando la dualidad de su existencia como mujer medio seglar (35 años), medio monja (23 años), nos pareció interesante para introducir al personaje, al menos para acercarse al recuerdo que dejó en sus convecinos decimonónicos: «La realidad se complace a veces en sobrepujar los más poéticos sueños de nuestra fantasía. (...) no podría concebir (...), un carácter tan ideal, una figura tan delicadamente bella, como el carácter y la figura que la realidad, para honra y orgullo de Cádiz, formó en ese prodigio de hermosura a quien la admiración de sus contemporáneos dio el nombre de Hija del Sol».

José del Toro presentó a la poetisa como el orgullo de su ciudad, como una mujer rica, hermosa, adulada. La calificó de «alma elevada y digna», recalcando su inteligencia viva y despejada. Insistió en su «sensibilidad exquisita», en los valores de «un corazón que latió siempre al impulso del amor, de la amistad y de los nobles sentimientos», atribuyéndole una «cabal armonía en un cuerpo modelo de perfección y belleza.» (Toro y Quartielles, 1881: 238)

No hay la menor duda, esta monja casada (profesó con la autorización de su marido) amaba la lectura antes de vestir el velo, era curiosa de todo, estudiosa, rodeada de astrónomos, matemáticos, médicos y eclesiásticos de renombre. No sólo sabía escribir sino que era aficionada al arte de la heráldica, con una caligrafía de prestigio, cercana a la de sus amigos escribanos. Su creatividad, en el arte de escribir, la descubrimos en los libros conservados en el monasterio de Santa María del Arrabal en el que profesó. Su manera de presentar las cuentas, por sus frecuentes extravagancias caligráficas de carácter festivo, musical, incluso bélico, consiguieron transformar ese árido trabajo en unos libros de cuentas de lectura amena, en ocasiones verdaderas obras de arte. Su consulta no permite poner en tela de juicio el talento y las ganas de aprender de la Madre Cruz a lo largo de su existencia.

Tanta ilustración en cuerpo de mujer a mediados del XVIII se la debió a su entorno familiar. Fue hija y nieta de negociantes irlandeses de distinguida 
alcurnia. Una realidad conocida por el director de La Academia: «Gozando su familia de posición desahogada, amada por sus padres, respetada y considerada por los extraños, el mundo se le ofreció desde luego con todos sus atractivos (...) Recibió esmeradísima educación, y desde muy joven, en delicadas poesías, incorrectas y descuidadas en la forma, pero mostrando en su fondo todo el vigor y todo el entusiasmo de un alma creada sólo para amar, expresaba sus afectos con encantadora ingenuidad y con singular gracia».

Tenemos el juicio que nos interesa. Podemos apreciar una primera opinión crítica sobre su lírica, interesante, aunque no compartamos la visión decimonónica.

\section{EL ANÁLISIS DE ALGUNOS DE SUS TEXTOS MANUSCRITOS E IMPRESOS}

Para argumentar la rápida apreciación del director de La Academia, interesémonos por algunas de sus composiciones. Respecto de la originalidad, varios poemas de tipo anacreóntico destacan no por el uso de la forma empleada, habitual en sus contemporáneos, sino por su contenido. De los doce poemas anacreónticos conocidos, casi todos son de carácter profano. Para el estudio destacaremos a tres de ellos: dos manuscritos anteriores a su ingreso en la Orden de la Concepción (1778) y un tercero, publicado en prensa tras vestir el velo, poco después de ser sacristana y antes de supervisar oficialmente las cuentas del monasterio.

Estudiaremos conjuntamente los dos poemas manuscritos. El primero, por orden de creación, carece de título; sin embargo, la temática resultó fácilmente identificable por la frase introductoria: «Al poner unas flores después de amortajado, a un hijo que se le murió de viruelas». Contra todo pronóstico teníamos una anacreóntica con acento funesto. El poema titulado «El Nido», estructurado en dos partes, resultó ser inseparable del primero; la distorsión temática de la atrevida poetisa, respecto de los temas habituales en los versos de Anacreonte, el Amor, la Amistad y el Vino, desvela su audacia y capacidad de creación ya en la década de 1770 .

El tercer poema se publicó en prensa en 1795, casi dos décadas después de su velorio. Se titula «La ensalada» como el género musical muy de moda en la Península durante el Renacimiento. Estos versos ofrecen otra orientación de su osadía poética; si no la distorsión temática, mayor innovación en cuanto al uso de los tópicos latinos del Beatus ille y Locus amoenus, es decir, de la vida retirada y evocación de la naturaleza.

En relación a las influencias medievales, el Stabat Mater Dolorosa supone un argumento poco común en el ámbito literario de los ilustrados de su 
tiempo. Esta composición de versos traducidos del latín y su respectiva glosa resultó ser su mayor éxito literario. Es desde el ángulo de la originalidad y no desde el análisis litúrgico (Morand, 2006: 579-607) que nos acercaremos al texto. MG de la $\mathrm{CH}$ (como le gustaba firmar) eligió, en vez del modelo imperante entre sus contemporáneos, una de las obras maestras del arte poético religioso medieval para crear. El estudio comparativo de la traducción del Stabat con la de Lope de Vega insertada en sus «Soliloquios amorosos de un alma a Dios» (1626) nos pareció pertinente para destacar la capacidad de creatividad de la religiosa.

Por otra parte, la glosa al Stabat se podría contemplar desde el ángulo de las «mejores falsificaciones», según la expresión de Álvarez Barrientos al discurrir sobre plagio y antimodernidad en la República de las Letras (Álvarez Barrientos, 2009: 7). Porque, al parecer, ese fue el método empleado por la astuta gaditana para componer esta dinámica e insólita creación.

\section{ORIGINALIDAD EN VERSOS}

Vayamos por partes. Empecemos por los poemas de índole neoclásica. Tras observar la cantinela titulada «A un pajarillo» del riojano Esteban Manuel de Villegas (1589-1669) - quien tradujo e imitó a Anacreonte - se pueden apreciar claras influencias en la poetisa. Ofrezcamos un extracto de dicha breve composición y saquemos provecho de la canción de Villegas para establecer algún paralelismo con el poema manuscrito titulado «El Nido».

/Yo ví sobre un tomillo/quejarse un pajarillo,/viendo su nido amado,/de quien era caudillo,/de un labrador robado,/Vile tan congojado/por tal atrevimiento/ dar mil quejas al viento,/para que el cielo santo/lleve su tierno llanto,/jlleve su triste acento./ (Villegas, 1845: 132-133).

El «yo» poético es testigo de la desgracia de un pájaro ante la vil actuación del ser humano y la sustracción del nido. La poetisa se sirvió de esa misma temática, bastante común, por cierto; sin embargo, aparece más y mejor definida. Para empezar, no es pájaro cualquiera sin sexo sino una golondrina, una madre y sus polluelos escenificados, eso sí, en un universo campestre idílico propio del género. El nido no está en un árbol sino en un hueco, a escondidas. Asimismo, el texto no sólo se hace más largo y más genuinamente descriptivo por la activa preparación del nido, la deliciosa espera del nacimiento y la fuerte carga de amor maternal trasmitida sino que el ritmo del poema se confunde con el entusiasmo de un «yo» mucho más alegre, mucho más espontáneo para luego volverse más angustioso, más sentido, más profundo. El uso del verso corto, el hexasílabo, más incisivo que el heptasílabo de Villegas, le permite aumentar sustancialmente el ritmo y la angustia vivida por la madre golondrina. 
En palabras de los Enciclopedistas, las virtudes de las jóvenes golondrinas eran muy acreditadas en la pasión histérica, en las convulsiones y, lo que nos interesa, en los partos difíciles, aunque muchos médicos aseguraban que los efectos no correspondían con su pretendida celebridad. En el arte de la heráldica, la golondrina representa el símbolo de la ternura maternal (Diderot y D'Alembert, VIII. 219.b. y Suppl. III. 429.a.).

Por sus conocimientos en ciencia heráldica y en medicina (fue acompañante de médico en el convento), la elección de la golondrina no puede ser casual, razón por la que abordamos conjuntamente el estudio de las dos anacreónticas, la de su hijo muerto y «El Nido», por estar estrechamente ligadas, poética y temáticamente. La tragedia de esa madre golondrina es la de la poetisa. El tema de la Muerte (física y civil) es recurrente en su obra, y a menudo usa la imagen aparentemente ligera del pájaro - jilguero, canario, palomillo, perdiz - para expresar su infortunio.

En la anacreóntica a su hijo muerto no hay pájaro alguno sino el tormento de una madre que acaba de perder a su prole; una madre que sufre pese a las reglas de conducta social: «(...)/Entre tus fríos dedos,/conforme, sólo aplico/ esta flor, que retrata/la aflicción que reprimo.//Por lo que me has costado,/por lo que te he querido,/resistencia me implaca/el Hacedor divino/». Divisamos las dificultades del parto en una época en la que todavía no se tenía una explicación convincente de cómo el feto era expulsado del vientre de su madre tras nueve meses. La Hija del Sol es conmovedora; su lírica, sencilla y transparente, emociona: «/tomad, piadosa gente,/ya os entrego mi hijo,/y ni tocar su rostro/a mis labios permito./Ya su espíritu habita/en más dichoso sitio;/y tras sí se ha llevado/sentimiento y sentido/».

Lo que impresiona en esta composición es cómo la gaditana se atrevió a mezclar alegría técnica (la forma anacreóntica) con el sufrimiento (el fondo). No nos pareció torpeza alguna, según comentó el Director de La Academia, calificando sus poesías de «incorrectas y descuidadas en la forma», sino ganas de innovar, de trascender el género, de romper con los moldes establecidos por sus coetáneos. No sólo el uso de vocablos específicos permite determinar una corriente literaria u otra, sino las figuras de construcción así como las de pensamiento.

Probablemente fue más libre para crear que cualquier varón presionado por la necesidad de conservar la compostura literaria. El canon es masculino, no hay quien lo dude y la excepción, femenina si acaso. ¿Qué hombre se atrevió a escribir un poema a su hijo muerto usando el género anacreóntico?

Hace una década, Pierre L. Ullman publicó un interesante artículo en el que proponía un paralelo entre el poema «El Nido» y el elemento musical 
(las sonatas de Scarlatti y su proceso cíclico). A la vez, introducía el elemento pictórico para el estudio, los cuadros de Greuze y de Oudry, delicados ecos gráficos para ilustrar el tema del pájaro muerto (Ullman, 2000: 101-106). Este poema no es una composición corta como la de Villegas (27 versos) sino un largo poema, estructurado en dos partes ( 52 y 44 versos respectivamente). Al estilo de la tragedia, en tres o cinco actos, su drama sólo necesitó de dos: la exposición de la situación de los personajes, es decir, la preparación del nido para acoger el feliz acontecimiento, mientras que en el segundo acto aparece el elemento perturbador, causa de la muerte, sin necesidad de incluir un tercero en que, habitualmente, los protagonistas buscan solución al drama. Porque aquí la muerte no tiene solución.

Como en Villegas, detectamos la presencia de los adjetivos «triste» $\mathrm{y}$ «tierno», empleado una sola vez en el poema del riojano, hasta tres y dos veces por la gaditana. En Villegas el ladrón de pájaro es un labrador, un hombre adulto sin calificativo alguno mientras que, para ella, es un «muchacho infame», «aleve», «obstinado» en su «villana empresa».

Por otra parte, la voz poética de esta fémina dolorida se involucra con fuerza en el intento de salvación del nido, no es ningún testigo pasivo como en el texto de Villegas: «/percíbolo, grito,/corro en su defensa,/Mas no llegué a tiempo/que el pájaro apenas/de las vigas cae/y en mi pecho queda/ (...)/no puedo seguirlo/por el que me queda./La madre los mira/puesta en una teja/y en su triste canto/llora su tragedia/».

La presencia del «yo» se intensifica desesperadamente en la segunda parte (hay más de diez) ofreciendo mayor énfasis al drama; apunta su individualidad adueñándose del nido - «mi nido»- y acompaña de un profundo sentimiento de empatía la madre golondrina.

En cambio el «tú», en el segundo acto, se hace más escaso (dos) quizás porque el dolor, a diferencia de la alegría, no se comparte tan fácilmente. La presencia reiterativa de ese «tu» amante en la primera parte, ocho veces de los cuales cinco seguidas, antes de hacerse nominativo una sola y única vez - «Mirtilo»- traduce probablemente la necesidad de interlocución. El poema de Villegas carece de oyente externo: sólo el pájaro y el «yo» poético dialogan, y únicamente en la última estrofa. En el poema de la gaditana el dialogante es el elemento masculino. Cuando el denominado «amante» entra en el escenario gozoso es un «tú» activo y participativo. Es ese «tú», a quien se dirige el poema, el mismo que cierra y encierra la trágica composición entre dos versos, los dos últimos, los que abrieron el segundo acto de su infeliz creación: «/Y pues ya tú sabes/mi angustia y mi pena,/déjame que llore,/déjame que sienta/».

Anales, 23, 2011, pp. 67-93 
No sólo encontramos afinidad lírica con Villegas, su modelo muy probablemente, sino con su coetáneo Jovellanos. En 1786, el asturiano publicó un largo poema «A Arnesto» que debuta así: «/Déjame, Arnesto, déjame que llore/». Dotó el verso de mayor nobleza, prefiriendo el endecasílabo para expresar su cercanía con algunas ideas defendidas en carne y hueso por la poetisa. Él también defendió el matrimonio por amor en su comedia en prosa, El delincuente honrado, con el personaje de Laura, mientras que Gertrudis Hore vivió y pagó con su libertad tanto atrevimiento, hasta dejar a Batilo poéticamente asustado: «/Deja, Fenisa hermosa,qque goce de mi vida libremente,/ sin que turbe mi paz dulce y dichosa/el Amor inclemente./Fenisa, en vano quieres/pintarme sus placeres;/en él todo me asusta:/amado, la inconstancia temeraria,/y olvidado....jay Fenisa!.... moriría/» (Foulche-Delbosc, 1894: 183).

Pero ni el amor ni la muerte civil por razón de su vestidura son aquí el tema de nuestro propósito, sino los versos del asturiano, cuyo paralelismo al menos nos puede dejar algo perplejos: «/Déjame, Arnesto, déjame que llore/ los fieros males de mi patria, deja/que su ruina y perdición lamente/». Jovellanos convirtió estos endecasílabos en una ferviente crítica de los matrimonios y sus consecuentes disgustos, apuntando la infidelidad obvia de la esposa, la corrupción, el vicio y las futilidades de su época perdida entre modas y vanidades (Jovellanos, 1987: 197-204).

La materia del poema de Fenisa resulta bien distinta. No se inmiscuye ni defiende causas patrióticas, casi nunca lo hace. Su enfoque es de índole mucho más íntima, mucho más minimalista: «/Déjame que llore/Déjame que sienta/». Asistimos a la emergencia del «yo», el valor de la individualidad naciente en su estado más puro, manuscrito.

Pero la ciencia no es dogmática y sólo se trata de una hipótesis, una mera sugerencia para suscitar el debate y abrir camino, si fuera posible, hacia un mayor conocimiento de la creación literaria en España en el XVIII. Los poemas más antiguos de Jovellanos son de 1768, al igual que los de María Gertrudis Hore. La composición «El Nido» ha de ser anterior a su ingreso en el monasterio (1778); sabiendo que el texto de Jovellanos tiene fecha, aunque en materia de fecha es difícil afirmar con rotundidad, ¿podría haber sido el asturiano inspirado por la gaditana pese a que el poema no fuera impreso? Como bien es sabido, los manuscritos en el siglo XVIII circulaban con facilidad entre eruditos, sin necesidad de ser publicados.

Comentamos ahora la tercera y última anacreóntica de nuestro estudio. Sor Gertrudis firmó H.D.S. el poema titulado «La ensalada» en la prensa madrileña el 21 de mayo de 1795. Su atrevimiento, al no temer trascender las 
reglas que vedaban cualquier referencia en poesía que no fuese literaria, consiste en abordar un tema tan trivial como puede serlo una merienda. Para ello, se sirve de varios topos propios de la cultura grecolatina (Horacio, Virgilio) muy de moda en los clásicos del Renacimiento. El tópico literario del Beatus ille ensalza un tipo de vida sencilla y retirada en el campo, lejos de la ciudad, en armonía con la naturaleza. Asimismo, los temas del Carpe diem y Tempos fugit participan de la creación, y el uso del topos Locus amoenus constituye el escenario ideal para el desarrollo de la acción. Pese a recurrir a estos tópicos literarios de aspectos limitados, consigue darles nuevos aires, nuevas fragancias. Muy probablemente, en más de una ocasión, su atrevimiento literario se debió a su sólida formación musical. En este caso, podría ser Sebastián Aguilera de Heredia (1561-1627), entre otros compositores del quinientos, el culpable: denominó «Ensalada» a una de sus piezas para órgano por la multiplicidad de temas y estilos. Dicho género, madrigalesco y heterogéneo, se concibió para diversiones y fiestas palaciegas, tal y como Fenisa concibió «su ensalada», aunque de forma algo más selecta.

A diferencia de Fray Luis de León en su oda «A la vida retirada», máxime exponente del topos Beatus ille, según el cual se busca vivir en armonía con su propia conciencia, la Hija del Sol no busca soledad «/a solas sin testigo/», sino que expresa la necesidad de compartir ese fugaz y placentero retiro. El «yo» poético no pide anacoretismo, sólo abandona los placeres de la ciudad por un momento; describe el tentempié campestre en compañía de sus amigas aunque no se trate de una jira, porque regocijo quiere pero no bulla.

El «yo» poético huye del griterío humano propio de la urbe, tal y como lo exige el topos, aunque el bullicio, en este caso, lo ubique en un caserío: «/ De riñas y cuestiones/ardiendo está la Aldea,/todas hablan a un tiempo,/y no hay quien las comprenda/». De esa manera expone las desventajas si no de la metrópoli, de la aldea, e insiste en dichos inconvenientes antes de presentar las ventajas del campo, según su propia visión. No hay duda, el «yo» reclama con ansia el anhelado retiro: «/y yo a mi hogar me acojo/huyendo la refrie$\mathrm{ga} / »$. Asimismo, en su concepto del Locus amoenus existe seguridad y se puede apreciar la sencillez del confort pero no es terreno sombreado de bosque abierto. En busca del escenario idílico, ni rastro de prados verdes, tampoco de riachuelos cristalinos, ni de pájaros cantando, nada de céfiro o de algún árbol con agradable sombra en su composición. Lo que da sombra, lo que procura verdadera quietud a la voz poética es una cabaña en medio del monte, «mi hogar». Por tanto, prescinde de la escenificación al aire libre tan imperiosa en las composiciones de los siglos XVI y XVII. Finalmente, el campo no parece interesarle tanto como el retraimiento que ofrece. Es de notar que lo que el 
escritor y eclesiástico Antonio de Guevara transformó en Menosprecio de corte y alabanza de aldea (1539) tampoco se adapta a su creación, pese a que fuera la forma más habitual de tratar el topos en la segunda mitad del siglo XVIII (Carrasco: 1986, 81-93).

El propósito de la gaditana no tiene nada que ver con el discurso moral que opone los vicios de la urbe a la vida honrada del campo. Tampoco condena el lujo abiertamente, sino que formula cierta crítica social hacia la falta de educación de las mujeres: «/todas hablan a un tiempo,/y no hay quien las comprenda./Unas Zagalas gritan/por sus propias querellas,/y otras enardecidas/disputan las ajenas/». Ni hace elogio de la vida campestre, ni opone trabajo agrícola a la holgazanería, sino vanas conversaciones a reuniones placenteras alrededor de una mesa, aunque sólo fuese con un mantelillo tendido en el suelo. Sólo condena la mala educación de las damas; siguiendo al profesor Marti, es posible que en este poema de apariencia frívola realice una crítica muchos más radical de la supremacía social y sus ideales (Marti, 2001: 5).

Según la retórica latina, la descripción del paisaje sirve de marco ideal para el amor. En este caso, le sirve para el disfrute de la amistad entre mujeres y no hay descripción de paisaje. Es de notar que el poema se dirige y considera exclusivamente a las de su sexo. La presencia masculina se encuentra sólo al principio, en los versos 9 y 10 , con el uso de la palabra «mayoral», un vocablo usado por Jovellanos y criticado por Hermosilla por ser «demasiado familiares» (Lázaro, 1985: 221).

No aparecen aguas-fuentes ni ríos, aunque no falte el elemento líquido. Resultó ser el artefacto idóneo para oponer el griterío al sosiego de su interior en el campo: «/Y en tanto que ellas rabian/traéme tú, Filena,/con agua serenada/la talla portuguesa/». Es el agua conducto entre la bulla ciudadana y la naturaleza; «agua serenada» a la que elige dar un toque típicamente andaluz con el uso de la «talla portuguesa». Esa palabra que viene del portugués «talha», y a su vez del árabe «alcarraza» es propia de Andalucía: es una jarra de cuello estrecho que permite conservar el agua fresquita. De padres irlandeses, María Gertrudis Hore se siente profundamente andaluza, según se aprecia en otras de sus composiciones (Morand, 2007a: 255-258 y 353-355), y no duda en hacer uso de costumbrismo de cuando en cuando.

Por otra parte, ese fugaz momento de amistad femenina lo dirige ella, como si tuviese la batuta. Siempre fue mujer de poder, perteneciente a la clase dominante con múltiples bienes, varios criados y esclava desde su más tierna infancia. Según la observación hecha por el profesor Félix Carrasco sobre el sujeto del enunciado en la «vida retirada», la poetisa pertenece al tercer tipo, es decir, ella es «el propietario de la clase urbana». No es «el hombre de la 
Edad de Oro», tampoco «el sabio», ni «el labrador», es la que lo organiza todo (Carrasco, 1992: 830). Ella manda, acostumbrada a ser servida tanto en el siglo como en la clausura. Dirige la puesta en escena dando órdenes a su criada, y sobre todo, se asegura de que nadie venga a molestarlas: «/Niña, de la cabaña/cierra pronto la puerta,/y por que no la empujen/arrímala una piedra/».

Aparta el escenario al aire libre para recluirse en un lugar cerrado, incluso en el campo. Se encarga de que todo quede perfecto y para persuadir al lector que así fue, traduce en una verdadera explosión de colores esa merienda digna de los más llamativos bodegones; aunque no aparezcan perdices, ni manzanas, tampoco uvas sino rosquillas, cebolla, borraja, pimentillo, tomate, pepino y hojitas de pimienta. Consigue recrear un espacio idílico sin apenas usar los elementos tradicionales del topos y hace que el lector tenga impresión de dinamismo: «/Tiende ese mantelillo,/(...) aquí en la tierra, y luego/de rosquillas lo llena/Pon también la ensalada/aliñada y compuesta,/con la blanca cebolla/y la borraja fresca/».

Su originalidad se puede apreciar en el léxico empleado, así como en la estructura del mismo. A fuerza de sustantivos y verbos compone el ritmo de su versificación, mientras que se recomienda el uso de epítetos sensuales y efusivos como dulce, suave, tierno, delicado para cumplir con el tópico y su debida evolución en el siglo XVIII. Sin adjetivos apenas para hilar los versos, la anacreóntica se presenta con escasos epítetos. Contamos siete de los cuales tres fueron adjetivos de colores (blanco, rojo, verde). Porque «/ El rubí del tomate/y la esmeralda bella,/del pimentillo dulce/ como el /(...) ámbar del pepino/» los sustantiva. La abundancia de nombres y la parquedad de adjetivos pintan una acción continua en la que los ingredientes se nos ofrecen en su estado natural. Sin embargo, la descripción y preparación de tan deleitosa merienda recuerda la representación de un conjunto de joyerías (rubí, esmeralda, ámbar), conforme el estatus social de la poetisa, más que el sabor insípido o la amargura del pepino. La Madre Cruz no invierte en los componentes líricos habituales a mediados del setecientos sino que se siente libre para innovar, además de segura para publicar haciendo uso de su sólida formación musical para estilar versos. Lejos de las protestas de modestia y discreción que tanto se repiten en prólogos y otros textos de mujeres «escritos para ganarse la benevolencia del público y para legitimar una actividad que venía siendo patrimonio casi exclusivo de varones» (Urzainqui, 2006: LXIII), Hore no teme abrir su propia senda poética.

Respecto del uso del Carpe diem y Tempos fugit son nociones que emplea al final del poema con la locución latina que más ha adoptado en sus versos, dando mayor ritmo y entusiasmo a su composición: «/Ea, vamos muchachas,/ 
arrimaos aprisa/que se pasa la tarde,/que la noche se acerca/». Al igual que el maestro Fray Luis, compara su suerte con las de sus coetáneas en la urbe. La última estrofa hace eco a la primera: terminamos «en paz» lo que empezó «de riñas»; así se asegura el equilibrio perfecto entre la conducta asfixiante de las féminas fuera y el deleite del retiro en su cobijo silvestre: «/Y mientras que las otras/necedades alternan,/comamos y bebamos/en paz nuestra merienda/».

Su lírica sólo refleja sentimientos hacia sus coetáneas. Dicha anacreóntica, aparentemente ligera, se vuelve el espejo del paisaje interior de la autora, de su ser, de su forma de ser, de su sólida formación. La evolución del topos no sólo revela una nueva aprensión de la naturaleza sino que permite considerar la significación social del mismo. El ascenso de las nociones de individuo y de individualidad, en auge como valores de referencia a finales de la centuria, no dejaron indiferente a la sensible e inteligente poetisa gaditana. María Gertrudis Hore reúne todos los elementos para pertenecer a esta generación que empezó a dibujar los nuevos tiempos literarios, abandonando progresivamente el llamado «siglo de la razón» para deslizarse hacia el «siglo del sentimiento», preámbulo del romanticismo, aunque siempre resulte difícil ponerle una etiqueta por la pluralidad de sus creaciones, según descubriremos en el apartado siguiente.

\section{INFLUENCIAS MEDIEVALES EN LAS POSTRIMERÍAS DEL SETECIENTOS}

Si estudiar la originalidad del poeta e interrogarse sobre la integración de sus libros devotos en el conjunto de su obra en el siglo XVII es ahora incuestionable, no lo es para la literatura de finales del XVIII. De hecho, la devoción parece ausente del panorama literario y no es de extrañar: la llamada devotio moderna encuentra sus fuentes en el fervor espiritual del siglo XIII, cuyo lirismo se hace el heredero de la himnología medieval en el seiscientos (Amselem-Szende, 2003: 20-22). Sin embargo, el ideal de Philosophia Christi, cuyo dos guarismos eruditio et pietas combinan ideas platónicas y textos autorizados del Evangelio y de los Santos Padres, aún sigue vigente en el mundo cristiano del XVIII, y más si cabe en los claustros. El libro más leído todavía hoy por las religiosas es La imitación de Jesucristo de Thomas Kempis (1380-1471). No fue propiamente dicho el fundador de la devotio moderna pero sí el que propugnó nuevos ideales hacia un cristianismo más puro y sencillo, basado en una piedad auténtica y en el cultivo de la vida interior. Recurrir a la mayor versificación del movimiento espiritual de trascendencia social y artística durante la Edad Media revela sin duda el interés de nuestra ilustrada por esa antigua corriente tanto religiosa como social, política como literaria, llamada devotio moderna. 
Por tanto, y aunque sólo a primera vista escasean los ejemplos, no despreciemos la literatura devota en el setecientos. Del mismo modo, para ser más exactos, tendríamos que escudriñar en las creaciones de mujeres y, en particular, en las de varias religiosas. Ya es hora de que no sólo la «elite intelectual» represente el panorama cultural y literario español sino que, independientemente del sexo de sus autores, podamos disfrutar de un horizonte literario más amplio y más plural.

\section{LA ESTRUCTURA DE SU CREACIÓN Y LA DE LOS «SOLILOQUIOS»}

Por ahora, interesémonos brevemente en el armazón de dicha composición antes de comparar el poema en latín más citado, más traducido, más conmovedor y emocionante de la Pasión de Cristo, el Stabat Mater Dolorosa con la traducción realizada por Lope de Vega en sus «Sololiquios amorosos de un alma a Dios» (1626). En esta composición, cuyos argumentos fueron la atrición y búsqueda de la redención merced al dolor y al llanto, el «Monstruo de la Naturaleza» asocia versos y prosa, además de componentes autobiográficos en el tema de la penitencia, según demostró cabalmente la profesora Amselem-Szende.

La creación de la gaditana adopta un dinamismo litúrgico similar, heterogéneo, aunque ella permanezca mucho más cercana a la solemnidad y celebración del Santísimo Sacramento, sin necesidad de descripción ni relato hagiográfico (en su primera acepción). De hecho, en su composición no aparece el elemento amoroso como en Lope. Asimismo, la Madre Cruz se inspiró realmente en un texto del siglo XIII a diferencia de Lope que se presenta como el traductor de una obra que atribuye a un tal Gabriel Padecopeo, anagrama de Lope de Vega Carpio (Raynie, 2004: 65-72). Ella escoge el poema de Stabat Mater Dolorosa atribuido al monje italiano Jacopone da Todi para crear. Dicho poema en latín se añadió al Misal Romano en el año 1727 para que fuese cantado en día de Nuestra Señora de los Dolores, el 15 de septiembre; fue una de las pocas secuencias (musicales) en sobrevivir al Concilio de Trento. Además, la estructura elegida por la religiosa concuerda con las directivas encomendadas por Benedicto XIII (1724-1730) cuando instituyó una segunda fiesta anual de los Siete Dolores de María el Viernes de la semana de Pasión.

Por tanto, su particularidad, a la vez que el carácter profundamente dieciochesco de su composición, se debe a un acto de fusión entre la liturgia del Viernes de Pasión, según el Evangelio, y el uso del Misal para la Fiesta de los Siete Dolores. La Madre Cruz recuperó algo de la literatura medieval en la que la poesía era el elemento fundamental de la creación y, juntamente, estrechó su relación con la música y el canto gregoriano, el elemento monástico por 
excelencia en el desarrollo de la poesía sagrada, de los himnos y de las secuencias. Acordémonos, era diestra en música, al igual que lo fueron los primeros autores de Stabat. Aunque no estudiemos el texto en su totalidad, tengamos presente la estructura:

Himno a vísperas: La que nació fresca rosa (120 versos).

En latín y castellano.

La Misa es propia en honor de los siete dolores de la santísima Virgen.

En latín y castellano.

La Epístola es del capítulo XIII del libro de Judit. En latín y castellano.

Reflexiones: Nada puede aplicarse mejor a la santísima Virgen.

En castellano.

Secuencia: Stabat Mater dolorosa. (60 versos). En latín y castellano.

El Evangelio es del capítulo XIX de san Juan. En latín y castellano.

Meditación: De los dolores de la santísima Virgen. En castellano.

Jaculatorias. En castellano.

Propósitos: 1. Una compasión seca. 2. Es un ejercicio de devoción.

En castellano.

Así organizó su composición y, como en la creación de Lope, se aprecia fervor religioso, espontaneidad y atrevimiento literario. Empero, orden y disposición difieren bastante de la del madrileño. La gaditana también optó por una introducción en versos pero más solemne y de carácter litúrgico. No compuso soliloquios (7) como el Ingenio, tampoco terminó su creación con el Ave Maris Stella (Vega, 1778: 77), cien jaculatorias a Cristo en prosa (Vega, 1778: 78-90) y una versión castellana del Stabat Mater titulada «El llanto de la Virgen» (Vega, 1778: 91-92), sino que el poema del monje italiano ocupa el centro de su creación. Es con este poema con el cual realizaremos el estudio comparativo. No perdamos de vista la traducción latina, según versión oficial de la Iglesia, la de Jacopone da Todi, la utilizada por la Madre Cruz (Martín, 1998-2009).

Recordar en las postrimerías del setecientos el lugar ocupado por la Virgen María aunque hubiese libertad para hablar de la Madre de Dios, dio sin duda un nuevo impulso, un nuevo entusiasmo al credo. Según pudimos apreciar en la documentación archivística, convenía de cuando en cuando reavivar las creencias para asegurarse de la supervivencia del culto. Es de suponer que esa fue su intencionalidad. A no ser que fuera obra por encargo, por encargo del obispo, petición de la abadesa o bien simple deseo de la poetisa de componer alrededor de la advocación de su monasterio. Sea lo que fuere, una vez más, esta composición de índole profundamente devota no le impidió ser 
original y creativa. En palabras de la crítica franciscana: «Basten estos versos para reconocer que el paso de Sor Gertrudis por los dominios de la literatura dejó en su curso huellas luminosas. Muy parecida por el estilo elegante al Padre Colomer, armoniza en su pluma la fluidez jugosa del lenguaje, las delicadezas de la observación psicológica y las ternuras del sentimiento» (Eijan, 1935: 405-406). Bien es cierto, siguió la idea del franciscano Vicente Martínez Colomer (1762-1820), le imitó en el estilo y en la métrica (octosílabos), pero no dejo de brindar a su creación una perspectiva propia.

\section{ESTUDIO COMPARATIVO: EL STABAT MATER DE LOPE DE VEGA}

El Stabat Mater es un poema en latín de veinte estrofas de tres versos cuyas rimas siguen el esquema: aabccb. MG de la $\mathrm{CH}$ respetó en su totalidad la estructura rítmica del poema. En la composición de Lope encontramos dos versos de rimas a-a que se quedan en a-x: amor/dolor (v. 25-26) y llorar/lastimar (v. 37-38) (Vega, 1778: 91-92).

Los dos primeros versos del Stabat:

MG. de la CH. (v. 1-2)

La Madre estaba llorosa

Junto a la cruz dolorosa,

Lope de Vega

La Madre piadosa estaba

junto a la Cruz, y lloraba

Stabat Mater Dolorosa/Juxta crucem lacrymosa/. Como en la versión lopesca, la religiosa posiciona a la Madre primero, pero no le atribuye calificativo pío. A continuación, se sirve de la figura retórica que consiste en la disposición en cruz de dos sintagmas, el quiasmo, que establece entre la versión latina y su traducción, apropiándose de forma mucho más lírica del original para crear mayor emoción, además de constituir metafóricamente el dolor. Al contrario, Lope permanece más apegado al original. Seguimos:
MG. de la CH. (v. 4-6)
A cuya alma en tan gran pena
De tristeza y dolor llena
Dura espada atravesaba.

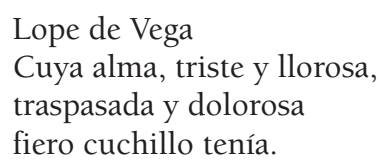

Lope de Vega

Cuya alma, triste y llorosa, traspasada y dolorosa fiero cuchillo tenía.

Como en la traducción latina la religiosa conserva la «espada» y como Lope le añade un adjetivo, «fiero» para él, «dura» para ella. Tanto en Lope como en el original la Virgen sigue llorosa. Lope lo traduce con una sucesión de epítetos (triste, llorosa, traspasada, dolorosa) mientras que la Madre Cruz obvia las lágrimas y los adjetivos y prefiere sustantivar la «pena», la «tristeza» y el «dolor» creando, quizás, mayor fluidez. Por otra parte, la elección del verbo «atravesar» brinda mayor énfasis al suplicio que el verbo «tener», aumentando la impresión de muerte en vida, de agonía. 
MG. de la CH. (v. 7-12)

¡Ô Dios! ¡cuán entristecida

Se encontraba esta afligida

Madre del Hijo mejor!

¡Y con qué melancolía

Las penas de su Hijo veía!

¡Cuántas ansias! ¡qué dolor!
Lope de Vega

¡O, cuán triste! ¡o cuán aflicta!

se vio la Madre bendita,

de tantos tormentos llena.

Cuando triste contemplaba

y dolorosa miraba

del Hijo amado la pena.

Los dos respetan las exigencias estilísticas del Stabat en estas tercera y cuarta estrofas pero María de la Cruz parece más entusiasta, más auténtica; acumula las exclamaciones (5), se aleja de la traducción latina con mayor desenfreno. Este primer verso de Lope sigue muy apegado a la traducción: «/¡O quam tristis et afflicta/ mientras que la monja exclama: ¡ Oh Dios! Cuán entristeci$\mathrm{da} / »$. Para Lope es la Virgen «/Madre bendita/(fuit illa benedicta)», marcando el carácter piadoso de la Madre de Cristo mientras que para ella es la «/Madre del Hijo mejor!/». Sor Gertrudis elige enfatizar la excelencia de su divina prole, alejarse de la traducción latina para crear, según la visión dieciochesca del concepto de traducción. El último verso es construcción propia, libre, en total empatía con el aflicción de la Virgen, sin verbo: «/¡Cuántas ansias! ¡qué dolor!/». El arrebato poético de Sor Gertrudis se muestra convincente; el estilo oral lleno de exclamaciones, cultivado con cierto énfasis por Lope en los «Soliloquios» (Amselem-Szende, 2003: 27), se nos ofrece en esta composición con fuerza, acento persuasivo e impresión de veracidad absoluta. Notemos el uso del término «melancolía»: «/¡Y con qué melancolía/» que se tradujo inicialmente por «/Languidecía y se dolía/» que Lope transformó en «/Cuando triste contemplaba/ (Quae maerebat et dolebat)». Ni rastro de la atrevida palabra en las demás versiones. Tal vez, se refería a esa «melancolía religiosa», acepción teológica según la cual personas de gran mérito, dignas de la mayor compasión, pasan por un trance «equivocado» al creer que sólo lágrimas y contrición, o sea, penitencia encauzan su razonamiento religioso. Este sentimiento de tristeza, si es exclusivo, no puede corresponderse con la contemplación debida al Ser Supremo, siendo éste fuente inagotable de felicidad y de serenidad (Diderot y D'Alembert, Tomo X: 308). Por tanto, la elección del arriesgado y audaz término, quizás, desee animar a la Madre de Dios en su infinita tristeza a fin de que recobre, incluso en tan difícil compromiso, Fe y Esperanza en su divino Hijo.

El siguiente verso (v. 13) resultó muy interesante: «/¿Quién el llanto contuviera/» dijo la religiosa mientras que Lope «/iY cuál hombre no llorara,» permanece, salvo el tiempo verbal, muy cercano al original: «/¿Qué hombre no lloraría/ (Quis est homo qui non fleret)». La visión de Sor Gertrudis, al reprimir las lágrimas, intensifica el dolor contenido. El uso del sustantivo «llanto», 
en vez del verbo, no hace más que aumentar el sentimiento de angustia del público testigo de la muerte del Redentor. Tampoco traduce «homo» por «hombre», como se podría esperar, sino por un «quién» en el que cabemos todos, incluso los más pequeños. Sencillamente, sus versos se hacen más patéticos, más sentidos, más profundos que las dos versiones que manejamos.
MG de la CH. (v. 13-15)
Lope de Vega
¿Quién el llanto contuviera,
¿Y cuál hombre no llorara,
Si a la Madre de Dios viera
si a la Madre contemplara
Puesta en tal desolación?
de Cristo en tanto dolor?

Si en el original el dolor de la Madre de Cristo era «suplicio», para Lope sólo es «dolor» mientras que para Gertrudis se vuelve «desolación». Capacidad de sugestión, conocimientos teológicos y la profunda percepción de empatía de la voz poética incrementan valiosamente el sentimiento de aflicción de María.

En la séptima estrofa, el «yo» poético es el único en no permanecer ajeno: «/Por pagar nuestro pecado/» dijo la gaditana mientras que en el original se lee: «/Por los pecados de su gente/» y en la traducción de Lope «/Por los pecados del mundo/». Sólo ella se involucra en la noción de redención del Salvador; y la fuerza del verbo «pagar» recuerda sin atajos el porqué de la Muerte de Jesucristo. Esta concepcionista, aunque fuese monja en las postrimerías del siglo XVIII, trasmite mayor ímpetu religioso, mayor fervor y entrega a la vez que se inscribe definitivamente en «una lógica personal y poética», según expresión de la profesora Amselem-Szende hablando de los «Soliloquios» de Lope (Amselem-Szende, 2003: 24). Es curioso notar cómo en sus creaciones de índole profana se puede fácilmente adaptar esa misma reflexión.
MG de la CH. (v. 25-27)
Lope de Vega
Ea, Madre, de amor fuente,
$¡ \mathrm{O}$ Madre, fuente de amor,
Pon a mi alma tan doliente hazme sentir tu dolor
Que te acompañe en tu llanto. para que llore contigo!

En esta novena estrofa constatamos cómo Lope prescinde de la interjección latina «Eja/Ea» o, mejor dicho, cómo la traduce a un lenguaje más común. La religiosa insiste en el amor de la Madre sin exclamarse y, una vez más, ofrece una construcción propia, distanciándose tanto de la traducción literal como de la versión lopesca. El «yo» se involucra en el dolor ( «mi alma tan doliente») y desea acompañar a la Madre en su martirio; al menos, así lo anhela en la estrofa catorce:

MG de la CH. (v. 40-42)

Junto a la cruz consolarte,

Y en tu llanto acompañarte

Quiero, Madre compasiva.
Lope de Vega

Porque acompañar deseo

en la cruz, donde le veo,

tu corazón compasivo. 
Si la «/Virgen de Vírgenes preclara/ (Virgo vírginum praeclara)» es «/Virgen de vírgenes santas/» para Lope, para la Madre Cruz es la «/que a todas excedes/». En esta estrofa número quince ansía la conversión y desea igualar a María mientras que Lope parece haber agotado o, al menos, debilitado el llanto:

MG de la CH. (v. 43-45)

Virgen, que a todas excedes,

Pues concedérmelo puedes,

Haz que llore cual tú lloras:
Lope de Vega

Virgen de vírgenes santas, llore yo con ansias tantas, que el llanto dulce me sea.

Sor Gertrudis no sólo desea llorar con María, sino llorar tanto como Ella. Y, para ello, le pide ayuda para «/Que logre mi alma mejoras/»(v. 48). Un verso traducido por Lope: «/que siempre sus penas vea/» cuyo enfoque se aleja de la enseñanza del Redentor.

Los distintos perfiles de vida influyeron sin duda en las trayectorias poéticas de índole religiosa de cada uno. Lope lleva, entre otros, el hábito secular de la Tercera Orden de Penitencia de San Francisco, la Madre Cruz viste el velo negro de las concepcionistas en un monasterio en el que desempeñó la función de sacristana. Y cada uno recuerda, a su manera, la impronta de sus vivencias con particular brío en la estrofa diecisiete.

Encontramos el verbo medular de la existencia de Lope, «enamorar»y ningún otro para sellar su fe en Jesús: «/Haz que su Cruz me enamore/». Mientras que Sor Gertrudis recuerda al lector, «/Siendo su cruz mi ejercicio/», su ministerio en el convento, su nombre de religiosa; se entrega con violencia a la Pasión de Cristo «/Hazme que viva en sus llagas/» y culmina con la figura retórica más emocionante de su traducción, «/su sangre ebrio/» recordando a Santa Catalina de Siena, según la cual la sangre de Cristo bebida permite al alma el despojo de sí mismo, el náufrago de cualquier sentimiento que no fuese el amor divino (Labande, 1918: 159-161).

MG de la $\mathrm{CH}$ (v. 49-51)

Hazme que viva en sus llagas,

$\mathrm{Y}$ de su sangre ebrio me hagas,

Siendo su cruz mi ejercicio.
Lope de Vega

Haz que su Cruz me enamore, y que en ella viva y more, de mi fe y amor indicio.

No es la cruz que le embriaga ( fac me Cruce inebriari») sino la sangre de Cristo, la que se consume en el sacrificio de la misa, metáfora sentida de la transubstanciación y emotiva alegoría de la Pasión. Lope prescinde de los sustantivos «llagas»y «sangre», ineludibles para ella; construye su fe y amor en Jesús no viviendo con él sino compartiendo, en lo más profundo de sus afectos, el dolor y la crucifixión del «Hijo mejor.»

Su deseo ardiente de compartir el fervor de Dios, complacerle y entregarse a él y a su Madre se aprecia ya en la décima estrofa. Quiere incendiarse 
«De amor de Dios», ser antorcha suya y arder para siempre y, por ello, esta vez, permanece cercana a la traducción del monje italiano ( «ut sibi complaceam»). El mismo vigor se vislumbra en la traducción de Lope aunque el enfoque se presenta de manera algo distinta. Él quiere despojarse de sí mismo para encontrarse en Dios como si entregara su ser al Hijo mientras que Sor Gertrudis sólo quiere empaparse de Él, de su amor.
MG de la CH. (v. 28-30)
Lope de Vega
Haz que arda mi corazón
Y que por mi Cristo amado
De amor de Dios, que es razón mi corazón abrasado
Pues eso le agrada tanto. más viva en él que conmigo:

En la estrofa número once persiste en su deseo de seguir fiel a las enseñanzas de Cristo en la Cruz, esa «cruz dolorosa» con la que se apellidó como lo hicieron los más fervientes representantes de la literatura española en los siglos XVI y XVII (San Juan de la Cruz, Sor Juana Inés de la Cruz), una elección sin duda nada anodina.

$\begin{array}{ll}\text { MG de la CH. (v. 31-33) } & \text { Lope de Vega } \\ \text { Haz que en mi alma estén de fijo } & \text { Y porque amarle me anime, } \\ \text { Las llagas del Crucifijo, } & \text { en mi corazón imprime } \\ \text { Porque nunca las olvide. } & \text { las llagas que tuvo en sí. }\end{array}$

«/Sancta Mater, istud agas,/Crucifixi fige plaga/Cordi meo valide/». Quiere fijar ese último ultraje en las profundidades de su alma, sin necesidad de usar el verbo «imprimir», sellar para siempre el rumbo de sus vivencias empapada de la vida y muerte de Cristo. Señalemos la intertextualidad interna respecto de las llagas (cf. Su Novena al Santo Cristo de la Esperanza) ${ }^{6}$. Aquí, la monja sustituye el cuerpo de Jesús, según y como se conoce la imagen del crucificado, en sinécdoque de la Pasión, instrumento de su sufrimiento: «/Las llagas del Crucifijo/» (v. 32).

Concluimos con la composición y su estructura. Aunque no recurra a los Milagros de la Virgen, probablemente leyó a Gonzalo de Berceo y su «Duelo que fizo la Virgen María el día de la Pasión de su Fijo Jesuchristo». En estos respectivos poemas, el de Todi y de Berceo, se privilegió el uso de los verbos. Con afán de comparación, decidimos contarlos en las tres versiones. Tarea inútil: no descuella simbólica alguna.

Contamos las expresiones «haz que»y «hazme». La gaditana conserva la estructura de la traducción literal en la que computamos seis «haz que»y dos

6. En esta Novena (1777), María Gertrudis eligió rezar cinco credos, en vez de los tres habituales, en memoria de las cinco Llagas del Señor; se identificó con la Pasión de Cristo, con el sufrimiento del Redentor haciendo hincapié en el infortunio y el dolor. 
«hazme», mientras que en la versión lopesca sólo aparecen dos y uno respectivamente. De los dos lexemas «hazme» contabilizados, Sor Gertrudis cambió uno, en la penúltima estrofa, interpelando directamente al «Hijo mejor» por «Haz, Cristo», lo que nos conduce a la presencia del «yo poético» en su discurso, empleado en tres ocasiones por la gaditana, en dos en la traducción literal y ni una sola vez por Lope: «/Haz, Cristo, en el postrer trance/Por tu Madre que yo alcance/La palma de la victoria/»(v. 55-57).

\section{¿PLAGIO O SUPLANTACIÓN?}

Varios fueron los factores que nos condujeron a descubrir cómo construyó esa dinámica y devota creación. Primero, fue en la revista Año Cristiano del Padre Jean Croisset que localizamos una de las reediciones de su traducción y glosa al Stabat publicado en Barcelona en 1863, dado que el original se conserva hoy en la «Hispanic Society of America». Por otra parte, sabíamos que estuvo en posesión de la colección no completa del Año Cristiano en su celda, según se recoge en su inventario postmortem (Morand, 2007b: 249-274). Asimismo, la disposición de la glosa al Stabat de Sor Gertrudis (Reflexiones, Meditaciones, Punto primero, Punto Segundo, Propósitos) correspondía con la distribución utilizada por esta revista traducida al español por los padres Joaquín Castellot y Joseph Francisco de Isla a finales del setecientos.

Así fue como empezamos a interesarnos en esta revista. Al consultar varias ediciones comprobamos cómo las publicaciones de finales del XVIII estaban compuestas únicamente de textos en prosa, mientras que las del XIX entrecortaban sus distintas reflexiones con poesías sagradas, tal y como la Madre Cruz decidió organizar su creación en la década de los 90.

Más tarde, en la biblioteca conventual de las religiosas de la Concepción de Cádiz hallamos trece tomos de la primera edición de 1791, además del tomo I del Suplemento de diciembre de 1793. Consultamos los distintos ejemplares a nuestro alcance en el monasterio y, más particularmente, el tomo III publicado en 1791, por curiosidad, porque empezaba el Domingo de Pasión hasta la Pascua de Resurrección. Pues bien, en el apartado del Viernes de la semana de Pasión encontramos la glosa al Stabat y su estructura idéntica, o casi idéntica a la que publicó. Calcó las ocho páginas del texto en prosa de esta publicación madrileña que sabía de difícil adquisición, tanto por el escaso número de lectores como por el precio de estos libros de buena pasta.

En el punto dos de sus «Propósitos» teníamos algunas correcciones. La primera, cuando el autor de la revista animó a sus lectores a rezar hasta el Viernes Santo el Stabat Mater Dolorosa: «Propón hacerlo desde hoy infaltablemente» escribió el traductor. Sor Gertrudis enmendó la incorrección, 
sustituyéndola por un «sin falta». Algunas líneas más abajo estaba escrito: «medita un misterio a cada decena del Rosario». Sor Gertrudis prefirió decirlo con algo más de precisión cambiando «cada decena» por «cada diez». Eran los únicos contrastes entre las dos publicaciones. Pero no copió servilmente la glosa sino que enmendó los defectos encontrados, a diferencia de Vargas Ponce en su Declamación (1793) cuando usó fragmentos y párrafos de Aldrete, de Mayans y demás autores transcribiendo hasta las erratas (Barrientos, 2009: 15). No estábamos ante un simple plagio, pasivo, sino que, atenta al texto transcrito, la poetisa aprovechó su creación para subsanar las faltas cometidas. Siguiendo la reflexión del profesor, «hay muchas formas de copiar y de hacerse con la obra de otro, lo mismo que hay bastantes razones para ello. No es lo mismo apropiarse una obra entera, que injertar frase y conceptos de otra u otras en la propia» (Barrientos, 2009: 9). Por tanto, ise consideró una copista servil y prefirió callar su superchería, o no lo confesó porque no pensaba serlo?

El profesor advirtió de la mucha erudición de un autor para conseguir que el texto plagiado sea desconocido de la mayoría. Existen «obras que pasan por ser auténticas y originales» y son «en realidad supercherías aún no descubiertas. Esas son, obviamente, las mejores falsificaciones y los mejores plagios» (Barrientos, 2009: 7).

Pero, ¿dónde termina y dónde comienza la obligación de confesar su plagio? María G. de la Cruz Hore copió la glosa del Viernes de Pasión, sin embargo, la combinó con nuevos elementos litúrgicos, dando valor y fuerza a esa prosa ajena; no vaciló a la hora de firmar su creación aunque, probablemente, no quiso poner fecha a su publicación por no «interferir» con la del Año Cristiano.

Desde la perspectiva dieciochesca se distinguía el timo con más o menos intensidad según fuera el de un autor antiguo o moderno, extranjero o compatriota, muerto o vivo. En este caso, Sor Gertrudis se hallaba en una de las peores situaciones: usó el texto de otro, compatriota vivo, sin mencionarlo y poco después de su publicación. Hizo suyas las palabras de Molière cuando dijo: «Recojo mi bien donde lo encuentro», como hizo suyas las Reflexiones y Meditaciones de Joaquín Castellot. Poseía todas las cualidades para apropiarse de texto ajeno, sin que nadie se diera cuenta a lo largo de más de doscientos años. Pese a todo, introdujo nuevos elementos (los poemas) e ideas propias (se sirvió de la Epístola, capítulo XIII, del libro de Judit en vez de las Lamentaciones de Jeremías propias del tiempo de Pasión). Lo cierto es que Sor Gertrudis dio a ese texto en prosa su verdadera dimensión: exaltó una idea que no era propia, es cierto, pero ofreciéndole nueva existencia. 
Según Reinelius y Thomasius, en su Dissertatio Philosophica de Plagio Literario (1673), desde un punto de vista moral el plagio era imperdonable mientras que desde «la perspectiva del bien colectivo (pro re publica)» podía «llegar a cumplir una función beneficiosa para la sociedad». El argumento, en desuso, pero válido en este caso, «no pecaría el plagiario, si amara a Dios más que a sí mismo» (Perromat, 2007: 4-5), sirve para recordar que, desde la perspectiva de la oratoria y de la poesía, el plagio no era delito si se superaba al modelo (Álvarez Barrientos, 2009: 14).

Por otra parte, la apropiación de un texto ajeno puede ser «la consecuencia de una fascinación. El que lee, el que investiga, es seducido por los datos, (...) por el modo de enunciar y se identifica hasta el punto de hacerlo suyo. Hay, por tanto, en ese caso, una suplantación» (Álvarez Barrientos, 2009: 7-8). Si se apropió la glosa era de suponer que este discurso le conmovió, le pareció muy ajustado y conforme a su pensamiento. Pese al descubrimiento de su maniobra literaria, tras estudiar detenidamente la composición en su totalidad, así como consultar varios números del Año Cristiano publicados en los siglos XVIII y XIX, no quedaba duda: trascendió el género al reunir poemas sagrados con la llamada literatura del sentimiento religioso. Imitar a fines del setecientos un escrito del siglo XIII había de ofrecer nueva relación con el texto, modificar el valor, el sentido y la utilización del modelo. Sor Gertrudis infundió dinamismo a esta preciosa composición medieval, respetó y siguió las enseñanzas del Evangelio, no se apartó un ápice de los preceptos y logró renovar el género.

La disposición y estructura de su composición forman una combinación de literatura moral con alto grado de religiosidad, un juego dramático por medio de la liturgia y de los misterios hábilmente integrados. Esta creación, con sabor a plagio, lejos de carecer de originalidad ofrece dentro del canon una nueva relación a medio camino entre invento y suplantación. Asimismo, decidió comprometerse social e institucionalmente al publicar esta larga plegaria en versos y prosas, dando pruebas de sus sólidos conocimientos litúrgicos, de su formación musical de calidad, así como de su perfecto dominio de la lengua latina y de su capacidad de creación ante un tema de tanta trascendencia para la Iglesia Católica. Sor Gertrudis seguía impregnando sus conocimientos de amplios volúmenes de carácter religioso, sin que estas lecturas le impidieran, sino al contrario, instaurar novedades y originalidad en sus textos.

\section{A MODO DE CONCLUSIÓN}

Acercarse a la obra de María Gertrudis Hore a través de algunas composiciones cuyas temáticas se sitúan entre el género anacreóntico y la traducción del 
Stabat Mater revela sus lecturas heterogéneas, su amplio espectro para crear, su inteligencia. La calidad de la traducción de la secuencia, hasta donde llegan nuestros conocimientos, es sin duda una de las más profundas, sinceras y auténticas que hemos leído para el estudio. Al igual que «La ensalada» se impregnó de su formación musical para componer versos, el Stabat fue el texto que más suscitó la industria lírica a lo largo de los siglos. Erudición, talento e ingenio se esbozan claramente en sus rimas pero, quizás, haga falta una lectura atenta para descubrir todo lo que encierran.

Nuestra intención no fue sobreponer sus composiciones a las obras y figuras de Villegas, menos si cabe a las de Fray Luis, Lope o Jovellanos, sino simplemente observar, comparar, proponer, intuir, sin establecer cerradas conclusiones sino procurando seguir caminando en los entresijos líricos de la gaditana, hija única de Miguel Hore y de María Ley, la que me fascina, me enseña, me obliga a leer de todo, a penetrar en terrenos desconocidos y sumamente atractivos desde hace tres lustros. Quería agradecer a Helena Establier el haberme invitado a participar en tan grata publicación. Gracias, Helena, lo he disfrutado.

\section{BIBLIOGRAFÍA}

Álvarez BarRIENTOS, Joaquín, «Plagio y antimodernidad en la República de las Letras: la denuncia de Juan Pablo Forner», Dieciocho, Anejo 4 (Spring 2009), pp. 7-17.

AMSELEM-SzENDE, Line, «Encarnación de Lope de Vega en los Soliloquios amorosos de un alma a Dios», Criticón, núms. 87-88-89 (2003), pp. 19-34.

BARABINO MACIA, María Rosario, Fray Juan Fernández de Rojas: su obra y significación en el siglo XVIII, Madrid, ed. Universidad Complutense, 1981.

CARRASCO, Félix, «Poemas a la vida retirada: sintaxis, semántica, ideología», en M.A Garrido (ed.), Crítica semiológica de textos literarios hispánicos: Actas del Congreso Internacional sobre Semiótica e Hispanismo, Vol. 2, Madrid, CSIC, 1986, pp. 81-93.

— «Beatus ille y la comedia clásica de labradores», en Antonio Vilanova (ed.), Actas del X Congreso de la Asociación Internacional de Hispanistas, Vol. 1, Barcelona, Promociones y Publicaciones Universitarias, 1992, pp. 827-839.

Diario de Madrid, lunes 9 de octubre de 1796, núm. 223, p. 905.

Diario de Madrid, «Juicio de los Diarios del mes de Mayo», lunes 8 de junio de 1795, núm. 159, p. 651.

Diario de Madrid, núm. 167, martes 16 de junio de 1795, pp. 681-683.

Diario de Madrid, «Concluye el Juicio de los Diarios de Agosto», domingo 9 de septiembre de 1795, núm. 252, p. 1026. 
DiDEROT y D'AlEMBerT, \&c, Encyclopédie, ou dictionnaire raisonné des sciences, des arts et des métiers (1751-1771), París, Librairie Le Breton (17 vols. y 4 supl.) CD-Rom: ed. Redon, Marsanne, 1999.

EIjAn, Samuel, Nuestros juglares del Señor. La poesía franciscana en España, Portugal y América. (Siglos XIII a XIX), Santiago, ed. «el Eco Franciscano», 1935.

Foulché-Delbosc, R., «Poesías inéditas de D. Juan Meléndez Valdés», Revue Hispanique, tomo 1, núm. 2, 1894, pp. 166-195.

FRANKLIN LEWIS, Elisabeth, Women Writers in the Spanish Enlightenment. The Pursuit of Happiness, Hampshire, Ashgate Publishers, 2004.

GÁlvez, María Rosa, Safo. Zinda. La familia a la moda, Madrid, Asociación de Directores de Escena de España, 1995.

Jovellanos, Gaspar Melchor de, Escritos literarios, Madrid, Espasa-Calpe, 1987.

Labande-Jeauroy, Thérèse, Les mystiques italiens: Saint Francois d'Assise, Sainte Catherine de Sienne, Jacopone da Todi, Paris, La Renaissance du Livre, 1918.

LÁzaro CARreter, Francisco, Las ideas lingüisticas en España durante el siglo XVIII, Barcelona, ed. Crítica, 1985.

LÓPEZ-CORDón María Victoria, «La fortuna de escribir: escritoras de los siglos XVII y XVIII», en Isabel Morant (ed.), Historia de la mujeres en España y América Latina, Tomo 2, Madrid, Cátedra, 2005, pp. 193-234.

MARTI, Marc, «La poésie peut-elle être un document historique? Le cas de la poésie lyrique néoclassique espagnole», Tiempos Modernos, Vol. 2, núm. 3 (2001), pp. 1-11.

MARTín Michael,W., 1998-2009. Versión latina del «Stabat Mater Dolorosa» de Jacopone da Todi; http://www.preces-latinae.org/thesaurus/BVM/SMDolorosa.html (última consulta el 16 de junio de 2010)

MORAND, Frédérique, «Nuevos datos acerca de las misteriosas razones de la toma de hábito de la Hija del Sol o el estudio de sus ignorados oficios», Dieciocho: Hispanic enlightenment, Vol. 32.2 (2009), pp. 387-412.

- Una poetisa en busca de libertad: María Gertrudis Hore y Ley (1742-1801). Miscelánea y taraceas de versos, prosas y traducciones, Cádiz, Diputación Provincial de Cádiz, 2007a.

- «La biblioteca de la poetisa gaditana Sóror María Gertrudis de la Cruz Hore (1742-1801)», Cuadernos de Estudio del Siglo XVIII, núm. 17 (2007b), pp. 249-274.

— «El «Stabat Mater» glosado y traducido por Sor María Gertrudis de la Cruz Hore a fines del siglo XVIII», Hispania Sacra, LVIII, núm. 118 (julio-diciembre 2006), pp. 579-607.

Perromat Augustín, Kevin, «Algunas consideraciones para el estudio del plagio literario en la literatura hispánica», Espéculo, núm. 37 (2007), pp. 1-13. http://www.ucm.es/especulo37/coplagio.htlm (última consulta el 14 de junio de 2010) 
QUINTANA, José Manuel, Ensayo de una Biblioteca de poetas del siglo XVIII, Madrid, Impresión Real, 1820.

RAYNIE, Florence, «Silencio pro Deo y elocuencia pro domo: San Bruno instrumentalizado por Lope de Vega», Criticón, núm. 92 (2004), pp. 65-84.

SimÓn PALMER, María del Carmen, Escritoras españolas del siglo XIX: Manual biobibliográfico, Madrid, ed. Castalia, 1991.

Toro y Quartielles, José del, «La Hija del Sol», La Academia, Año II, núm. 30, (20 de noviembre de 1881), p. 238.

Ullman, Pierre L., «Estructura Rococó y sensibilidad prerromántica de «El Nido» de María Gertrudis Hore», Salina, núm. 14 (2000), pp. 101-106.

URZAINQUI, Inmaculada (estud. prel.), «Catalin» de Rita de Barrenechea y otras voces de mujeres en el siglo XVIII, Vitoria-Gasteiz, Ararteko, 2006.

Vega CARPIO, Frey Lope Felix de, Colección de las obras sueltas, así en prosa, como en verso, tomo 17, Madrid, Antonio Sancha, 1778.

Villegas, Esteban de, Colección de trozos selectos de los más célebres escritores castellanos, tanto en prosa como en verso, Madrid, Imprenta de Doña J. Prados é hijos, 1845.

WALton, Julian C., «A Spanish poetess of co. Waterford origins», Old Waterford Society Decies, núm. 26 (summer 1984), pp. 41-44.

Zorrozua SANTISTEBAn, María del Pilar, Escritoras de la Ilustración española (1759-1808), Bilbao, Ed. Universidad de Deusto, 1999. (Tesis doctoral micro fichada)

Fecha de recepción: 09/04/2010

Fecha de aceptación: 07/05/2010

Anales, 23, 2011, pp. 67-93 